\title{
Study on Enhancing Lightning Protection Scheme of Catenary in Subway Viaduct Section
}

\author{
Rui-Fang Li*, Kui Chen ${ }^{\dagger}$, Li-Sheng Chen*, Xiao-Bin Cao*, Guang-Ning Wu* \\ and Xue-Qin Zhang*
}

\begin{abstract}
Viaduct increases the height of subway catenary, namely magnifies lightning attraction scope that lead to higher possibility of suffering lightning stroke. Therefore, it is necessary to analyze performance of lightning striking to catenary of subway in viaduct section and propose an improving lightning protection scheme. In this paper, using ATP-EMTP simulation software to establish an associated model to evaluate lightning withstand level of catenary with existing lightning protection schemes including arrester and grounding point, an improving lightning protection scheme is proposed - every pillar ground earth and arresters are installed with some installing spacing between $200 \mathrm{~m}$ to $400 \mathrm{~m}$ based on lightning damage degree and reliability requirements - according to analyzing results: while lightning withstand level is lowest for lightning striking to the neutral pillar, lightning withstand level is greatest for lightning striking to the both-ends pillar that arrester and grounding point are both installed; grounding point could obviously improve lightning withstand level for lightning striking to ground wire while arrester could obviously improve the lightning withstand level for lightning striking to catenary; every pillar ground earth could enhance the lowest lightning withstanding level up to 2.5 times than of that pillar ground earth across every $200 \mathrm{~m}$.
\end{abstract}

Keywords: Catenary of subway, Viaduct, Lightning protection scheme, Arrester, Grounding point

\section{Introduction}

Subway is provided with characteristics including a large traffic volume, high speed, security and reliability, punctuality and comfort, high efficiency, and the like, constructed vigorously in China in recent years [1-3]. Traction Power Supply System of subway (catenary / contact rail power supply) is required high reliability, however, there is no backup system for power supply that could lead to a permanent fault such as power outage once suffering lightning stroke [4]. The phenomenon of lightning activity emerges frequently in parts of china, so damages caused by lightning striking to insulators and electrical equipment extremely threaten safe and punctual operation of subway [5]. In Jinbin Light Rail, for instance, the quantities of damaged catenary insulators were over 60 due to lightning stroke from 2005 to 2006 , which is absolutely relative to interrupted traffic lasted for several hours at several times [6]. Catenary with viaduct has greater lightning attraction scope than without viaduct that could lead to be more vulnerable to lightning stroke, so it is necessary to enhance Lightning Protection Scheme (LPS).

For lightning striking to railway catenary, scholars have done extensive researches which focus on the railway risk assessment and early warning, effectiveness evaluation

$\dagger$ Corresponding Author: Dept. of Electrical Engineering, Southwest Jiaotong University, China. (ckcj911901@163.com)

* Dept. of Electrical Engineering, Southwest Jiaotong University,

China. (1rf lirf@swjtu.cn, cls workmail@qq.com)

Received: May 23, 2016; Accepted: October 28, 2016 of protecting railway catenary against lightning stroke, developing lightning shielding equipment and improving LPS in railway field, and so on [7-9]. Literature [10], combined with railway power supply model, analyzes the vulnerability of existing LPS and proposes recommendations on LPS of railway catenary. Literatures [11, 12], based on EGM, analyze the lightning attraction scope of catenary and assess the performance of lightning protection of the catenary, present the railway risk assessment and early warning. Literatures [13, 14], according to the structure and layout of the catenary and lightning protection requirements, develop parallel gap device used in lightning protection. Literature [15] studies the over-voltage characteristic generated in the cable for lightning striking to railway power supply system and proposes recommendations of grounding the cable armor layer. Literatures $[16,17]$ analyze the characteristics of lightning striking to integrated grounding system and propose improving methods.

These research achievements are principally based on ordinary railway, nevertheless, there are large differences between subway and ordinary railway on power supply system and lightning protection and grounding system [18] Subway's DC power supply $750 \mathrm{~V}$ and $1500 \mathrm{~V}$, far lower than $25 \mathrm{kV}$ AC voltage level used in ordinary railway [19]. The corresponding breakdown voltage of insulators for subway is generally around $100 \mathrm{kV}$ compared to $300 \mathrm{kV}$ of insulators for ordinary railway [20]. Dielectric strength of subway insulation system is lower than ordinary railway's, 
so supply lines for subway are more prospective of trip. Each pillar is grounding earth for lightning protection of ordinary railway while the ground wires are grounding earth with $200 \mathrm{~m}$ erecting spacing for subway, so lightning dispersed flow paths vary greatly between subway and ordinary railway. Above all, it is necessary to study Lightning Withstand Level (LWL) for enhancing LPS of subway with viaduct based on power supply system and lightning protection and grounding system.

In this paper, based on a viaduct project of subway in Guangzhou, establishing the model of lightning striking to catenary in ATP-EMTP software to evaluate the LWL with existing LPS, the effects on LWL could be discussed with various methods of grounding points and erecting arresters and an improving LPS is proposed.

\section{Analysis of LWL}

\subsection{Erection of catenary}

On a subway line, in Guangzhou, the length of firststage project is $54.3 \mathrm{~km}$ setting up 13 stations, including 4 ordinary stations, 7 viaduct stations, 2 transfer stations; The average, maximum and minimum distances between two stations of those are $4453 \mathrm{~m}, 5690 \mathrm{~m}$ and $2729.07 \mathrm{~m}$ respectively. The power supply system is of $110 \mathrm{kV} / 33 \mathrm{kV}$ two-level-voltage centralized power and the traction power supply system is of $1500 \mathrm{~V}$ DC power. The class of Insulation is considered as it is in seriously polluted area and the leakage distance is required not less than $250 \mathrm{~mm}$. Gapless zinc-oxide arrester with trip device is adopted and this kind of arresters has a discharge counting function. According to the actual requirements of traction power supply, simple stitched catenary, consisted of double carrier cable, double contact wire, 2 auxiliary feeders and a ground wire, is adopted at ground segments and viaduct segments. Catenary is made of $\mathrm{Cu}-\mathrm{Ag}$ alloy possessing good wear resistance, corrosion resistance and electrical conductivity (CTAH150). Ground wire is made of hard copper stranded conductors possessing good corrosion resistance and electrical conductivity (JT120). Carrier cables and auxiliary feeders are made of hard copper stranded conductors possessing good corrosion resistance and electrical conductivity (JT150). Fig. 1 shows the catenary with viaduct of subway, where the heights of ground wire, catenary and viaduct are $16.5 \mathrm{~m}, 13.6 \mathrm{~m}$ and $8 \mathrm{~m}$ respectively.

In Guangzhou, existing LPSs for viaduct of subway are ground wire, arrester and discharge gap. Ground wire is set beside positive catenary(both up and down lines), all metal grounding parts which normally insulated from live parts, including metal base, cantilever base, scattered pillar or davit and so on, are connected to ground wire. Ground wire is connected to grounding busbar in traction substation constituting flashover protection circuits. Viaduct piers are used as natural grounding substances whose grounding resistance is less than $10 \Omega$. Ground wire is erected across the whole line grounding through discharge gap. It is $200 \mathrm{~m}$ between two grounding points. Arresters are set at $200 \mathrm{~m}$ interval in the ground segments, viaduct segments, transfer tracks and testing lines. Staggered arrangement of arresters is in two-lane section.

\subsection{Model of lightning striking to catenary (MLSC)}

The catenary with viaduct of subway in Guangzhou follows design standard [18]. One LPS is adopted that arresters and grounding points of ground wire are set at $200 \mathrm{~m}$ interval. Arrester's (rated voltage of $1500 \mathrm{~V}$, model HY10WL-2.0/4.8) volt-ampere characteristic curve is as shown in Fig. 2. Minimum creepage distance and 50\% flashover voltage of pillar insulators are $250 \mathrm{~mm}$ and $100 \mathrm{kV}$ respectively. The insulators could be equivalent to voltage-controlled switches in ATP-EMTP software.

MLSC is established based on parameters of the subway line in Guangzhou, as shown in Fig. 3. The spacing between two pillars is $50 \mathrm{~m}$. L1 and L2 respectively represent the inductance per unit length of pier and viaduct surface, whose value are $0.5 \mu \mathrm{H} / \mathrm{m}$ and $0.15 \mu \mathrm{H} / \mathrm{m}$ respectively. $\mathrm{R} 1$ represents the resistance of NO.1 pier, whose value is $4 \Omega$. Wave impedance of each pillar takes the value of $150 \Omega$. N1

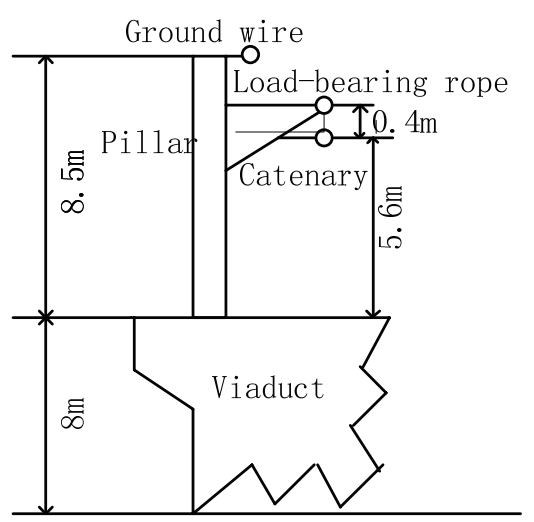

Fig. 1. Catenary with viaduct of subway

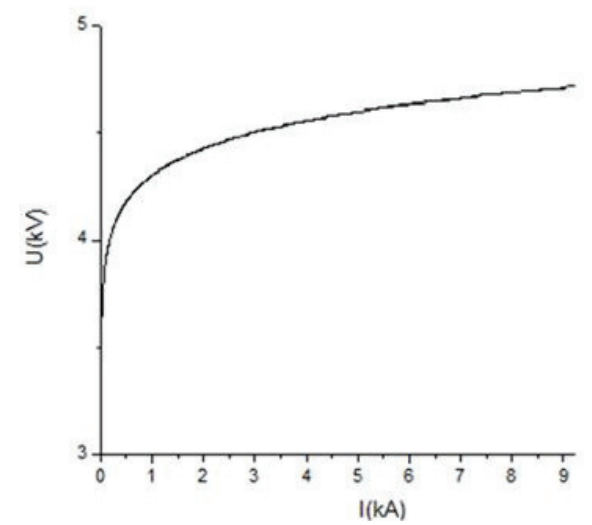

Fig. 2 Arrester's volt-ampere characteristics 
Table 1. LWL with existing LPS for lightning striking to ground wire at each pillar

\begin{tabular}{c|c|c}
\hline Striking point & Breakdown insulator & LWL \\
\hline NO.3 pillar & NO.6 insulator & $6.7 \mathrm{kA}$ \\
\hline NO.4 pillar & NO.5 insulator & $3.5 \mathrm{kA}$ \\
\hline NO.5 pillar & NO.5 insulator & $2.9 \mathrm{kA}$ \\
\hline NO.6 pillar & NO.5 insulator & $3.5 \mathrm{kA}$ \\
\hline NO.7 pillar & NO.4 insulator & $6.7 \mathrm{kA}$ \\
\hline
\end{tabular}

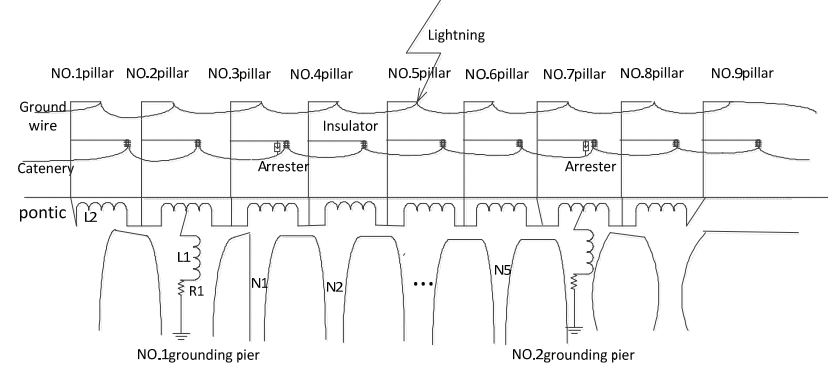

Fig. 3 MLSC of subway

to N5 represent ungrounded piers between NO.1 and NO.2 grounding piers.

\subsection{LWL of catenary with existing LPS}

This part analyzes LWL of catenary based on established MLSC according to different situations of lightning striking to ground wire. Lightning strike points are located on the top of NO.3 to NO.7 pillars respectively while the arresters and grounding points are invariably located on NO.3 and NO.7 pillars. LWL of each pillar can be evaluated as shown in Table 1.

Table 1 illustrates that the LWL for lightning striking to NO.3 or NO.7 pillars is the highest $(6.7 \mathrm{kA})$ due to arresters and grounding points on them. In other words, arresters and grounding points scatter lightning surge against insulation breakdown. The lowest LWL (2.9kA) occurs when lightning strikes to NO.5 pillar. The flashover also occurs on NO.5 pillar when lightning strikes to NO. 4 and NO. 6 pillars. The NO.5 pillar is at the middle point between grounding points or arresters that causes weakest protection, so the associated LWL is certainly the lowest. Only both the grounding point and arrester are set at NO.3 and NO.7 pillars that primarily causes symmetric distribution of LWL - strongest protection emerges at both ends, the associated LWL is the highest and the weakest protection emerges at the middle, the associated LWL is the lowest.

For studying insulator breakdown process, the voltages on insulators of NO.4, NO.5 and NO.6 pillars are analyzed when lightning striking to NO.5 pillar, as shown in Fig. 4.

Fig. 4 illustrates that the voltages on insulators of NO.4, NO.5 and NO.6 pillar uprise rapidly at the beginning of lightning stroke. The voltage on insulator of NO.5 pillar firstly rise up to $100 \mathrm{kV}$ that lead to associated insulator
Table 2. LWL with existing LPS for lightning striking to catenary at each pillar

\begin{tabular}{c|c|c}
\hline Striking point & Breakdown insulator & LWL \\
\hline NO.3 pillar & NO.6 insulator & $6.0 \mathrm{kA}$ \\
\hline NO.4 pillar & NO.4 insulator & $2.7 \mathrm{kA}$ \\
\hline NO.5 pillar & NO.5 insulator & $1.5 \mathrm{kA}$ \\
\hline NO.6 pillar & NO.6 insulator & $2.7 \mathrm{kA}$ \\
\hline NO.7 pillar & NO.4 insulator & $6.0 \mathrm{kA}$ \\
\hline
\end{tabular}

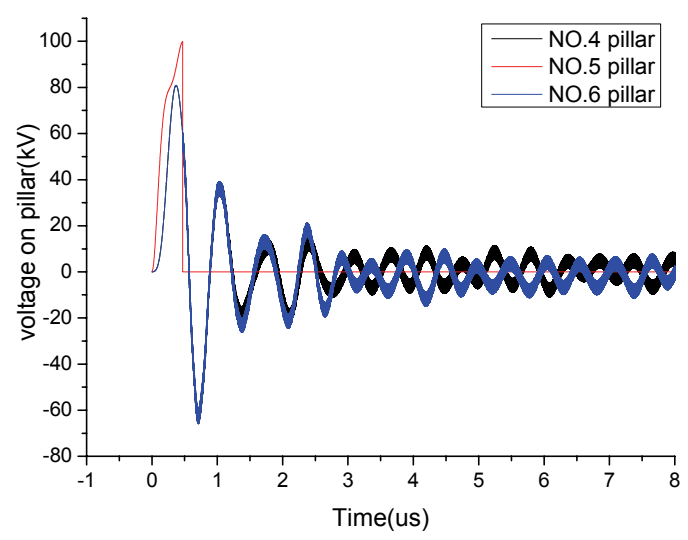

Fig. 4 Voltages on insulators

breakdown, then the voltage is down to $0 \mathrm{kV}$ rapidly. However, the voltages on insulators of NO.4 and NO.6 pillar are nearly the same due to their symmetric distribution beside insulator of NO.5 pillar. The voltages on insulators of NO.4 and NO.6 are dying out of oscillation after breakdown occurring on insulator of NO.5 pillar. So eventually breakdown only occurs on insulator of NO.5 pillar, nor the insulators of NO.4 pillar and NO.6 pillar.

This part analyzes LWL for insulators based on established MLSC according to different situations of lightning striking to catenary. Lighting striking points are located on the catenary of NO.3 to NO.7 pillars. LWL of each pillar can be evaluated as shown in Table 2 .

Table 2 illustrates that the LWL for lightning striking to NO.3 and NO.7 pillars are the highest (6kA). The lowest LWL (1.5kA) occurs when lightning strikes to NO.5 pillar. LWL also distributes symmetrically from NO.3 to NO.7 pillars. In other words, strongest protection emerges at both ends, the associated LWL is the highest and the weakest protection emerges at the middle, the associated LWL is the lowest.

\subsection{The maximum lightning current of catenary with existing LPS}

Lightning protection scope of double-line railway with ground wire based on EGM is as shown in Fig. 5. Point $C$ and point $\boldsymbol{C}^{\prime}$ both are representative of suspension point of carrier cable. Point $\boldsymbol{S}$ and point $\boldsymbol{S}^{\boldsymbol{\prime}}$ both are representative of erection point of ground wire. Point $\boldsymbol{A}$ is the intersection of lightning protection scope of ground wires at double 


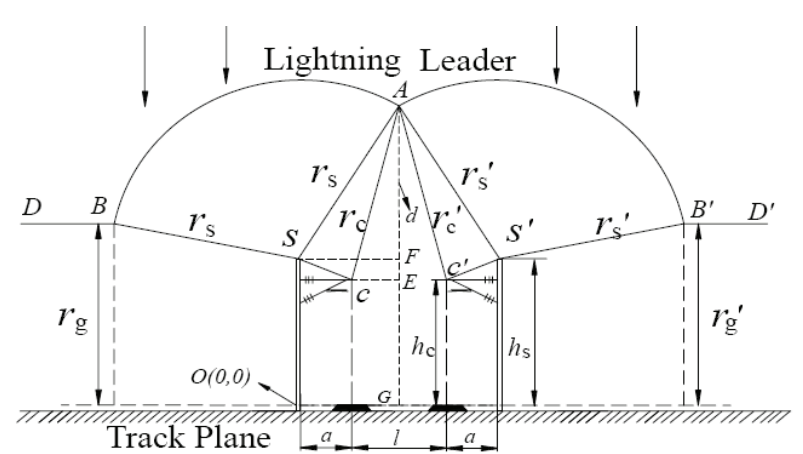

Fig. 5 Lightning protection scope of double-line railway with ground wire based on EGM

sides. $\boldsymbol{r}_{\boldsymbol{s}}, \boldsymbol{r}_{\boldsymbol{c}}$ and $\boldsymbol{r}_{\boldsymbol{g}}$ are respectively striking distance for lightning striking to ground wire, carrier cable and ground on the left along the double-line railway; $\boldsymbol{h}_{\boldsymbol{s}}$ and $\boldsymbol{h}_{\boldsymbol{c}}$ are respectively the erection height of ground wire and carrier cable evaluated as $8.5 \mathrm{~m}$ and $6 \mathrm{~m}$; Obviously because of the symmetrical distribution as shown in fig.5, $\boldsymbol{r}_{\boldsymbol{s}}=\boldsymbol{r}_{\boldsymbol{s}}{ }^{\prime} \boldsymbol{r}_{\boldsymbol{c}}=\boldsymbol{r}_{\boldsymbol{c}}$, $\boldsymbol{r}_{\boldsymbol{g}}=\boldsymbol{r}_{\boldsymbol{g}} ; \boldsymbol{l} \boldsymbol{l}$ is horizontal distance between the left lane and the right lane which is value of $4.4 \mathrm{~m}$. $\boldsymbol{a}$ is horizontal distance between suspension point of carrier cable and corresponding pillar which is value of $2.85 \mathrm{~m}$; $\boldsymbol{d}$ is the vertical distance from point $\boldsymbol{A}$ to the plane where the track is stood, specified by equation (1) as follows :

$$
d=\sqrt{r_{c}^{2}-l^{2} / 4}+h_{c}
$$

$\boldsymbol{r}_{\boldsymbol{c}}$ is maximum striking distance related to catenary for indirect lightning stroke corresponding to maximum lightning current. Corona effect could be ignored due to low voltage level of catenary system. Striking distance could be evaluated as recommended by literature [21].

Considering intersection of left pillar and track plane as the origin, a Cartesian rectangular coordinate system could be established. Coordinates of left and right carrier cable are $\boldsymbol{C}\left(\boldsymbol{a}, \boldsymbol{h}_{\boldsymbol{c}}\right)$ and $\boldsymbol{C}^{\prime}\left(\boldsymbol{a}+\boldsymbol{l}, \boldsymbol{h}_{\boldsymbol{c}}\right)$ respectively; coordinates of left and right ground wire are $\boldsymbol{S}\left(0, \boldsymbol{h}_{\boldsymbol{s}}\right)$ and $\boldsymbol{S}^{\prime}\left(2 \boldsymbol{a}+\boldsymbol{l}, \boldsymbol{h}_{\boldsymbol{s}}\right)$ respectively; coordinates of point $\mathrm{E}$ and point $\mathrm{F}$ are $(\boldsymbol{a}+\boldsymbol{l} / 2$, $\left.\boldsymbol{h}_{\boldsymbol{c}}\right)$ and $\left(\boldsymbol{a}+\boldsymbol{l} / 2, \boldsymbol{h}_{\boldsymbol{s}}\right)$ respectively. Equation (2) could be achieved.

$$
\left\{\begin{array}{l}
(a+l / 2-a)^{2}+\left(d-h_{c}\right)^{2}=r_{c}^{2} \\
(a+l / 2-0)^{2}+\left(d-h_{s}\right)^{2}=r_{s}^{2}
\end{array}\right.
$$

According to Eq. (1) and Eq. (2), the maximum lightning current could be evaluated by equation (3).

$$
\mathrm{I}=10 \frac{\log _{10} \sqrt{h_{s}^{2}+d^{2}-2 h_{s} d+(a+l / 2)^{2}}-1}{0.65}
$$

As above, the value of maximum lightning current is $0.427 \mathrm{kA}$. This low value indicates that the probability for lightning striking to catenary is tiny. Nevertheless, lightning leader propagation is stochastic so that catenary also could be stroke by lightning according to fractal theory.

\section{LWL with Different Installing Spacing Between Two Arresters}

\subsection{LWL with 300m installing spacing}

Here keep the $200 \mathrm{~m}$ erecting spacing between two grounding points recommended by standard and other conditions, except for the installing spacing between two arresters. It means grounding point is still set at NO.3 and NO.7 pillars. LWL can be evaluated based on established MLSC when lightning strikes to ground wire or catenary at each pillar. It adopts $300 \mathrm{~m}$ spacing to install arresters, namely arrester is set at NO.3 and NO.9 pillars.

Lightning strike points are located on the top of NO.3 to NO.9 pillars when lightning stroke occurs on ground wire. LWL and breakdown situations of insulators can be evaluated, as shown in Table 3.

Table 3 illustrates that the lowest LWL (2.8kA) occurs when lightning strikes to NO.5 pillar with $300 \mathrm{~m}$ installing spacing between two arresters. The highest LWL (6.5kA) occurs when lightning strikes to NO.3 or NO.7 pillar due to grounding point on the both, which provide lightning dispersed flow paths. As can be also noticed, LWL improves a bit for lightning striking to NO.9 pillar because of installing arrester on it.

Lightning strike points are located on catenary beside insulators of NO.3 to NO.9 pillars for lightning shielding failure. LWL and breakdown situations of insulators can be evaluated, as shown in Table 4.

Table 4 illustrates that the lowest LWL (1.2kA) occurs

Table 3. LWL with $300 \mathrm{~m}$ installing spacing of arrester for lightning striking to ground wire at each pillar

\begin{tabular}{c|c|c}
\hline Striking point & Breakdown insulator & LWL \\
\hline NO.3 pillar & NO.6 insulator & $6.5 \mathrm{kA}$ \\
\hline NO.4 pillar & NO.5 insulator & $3.4 \mathrm{kA}$ \\
\hline NO.5 pillar & NO.5 insulator & $2.8 \mathrm{kA}$ \\
\hline NO.6 pillar & NO.5 insulator & $3.2 \mathrm{kA}$ \\
\hline NO.7 pillar & NO.6 insulator & $6.5 \mathrm{kA}$ \\
\hline NO.8 pillar & NO.8 insulator & $4.0 \mathrm{kA}$ \\
\hline NO.9 pillar & NO.5 insulator & $3.4 \mathrm{kA}$ \\
\hline
\end{tabular}

Table 4. LWL with $300 \mathrm{~m}$ installing spacing of arrester for lightning striking to catenary at each pillar

\begin{tabular}{c|c|c}
\hline Striking point & Breakdown insulator & LWL \\
\hline NO.3 pillar & NO.6 insulator & $5.8 \mathrm{kA}$ \\
\hline NO.4 pillar & NO.7 insulator & $1.8 \mathrm{kA}$ \\
\hline NO.5 pillar & NO.5 insulator & $1.6 \mathrm{kA}$ \\
\hline NO.6 pillar & NO.6 insulator & $1.2 \mathrm{kA}$ \\
\hline NO.7 pillar & NO.7 insulator & $1.5 \mathrm{kA}$ \\
\hline NO.8 pillar & NO.7 insulator & $1.9 \mathrm{kA}$ \\
\hline NO.9 pillar & NO.6 insulator & $3.5 \mathrm{kA}$ \\
\hline
\end{tabular}


for lightning shielding failure of catenary beside NO.6 pillar, it is most likely to flashover on the insulator of NO.6 pillar. The highest LWL (5.8kA) occurs for lightning shielding failure of catenary beside NO.3 pillar because of grounding point and arrester on this pillar. Beside NO.9 pillar, LWL (3.5kA) improves due to arrester on NO.9 pillar. However, beside NO.7 pillar, grounding point of NO.7 pillar have nearly no effects on LWL. It can be concluded in these cases that installing arrester improves LWL and grounding point has nearly no effects on LWL for lightning shielding failure of catenary.

\subsection{LWL with various installing spacing}

For studying how the installing spacing between two arresters dose affect LWL, this part comparatively analyzes the lowest LWL under various installing spacing, including $200 \mathrm{~m}, 300 \mathrm{~m}, 400 \mathrm{~m}, 600 \mathrm{~m}, 800 \mathrm{~m}$ installing spacing. The erecting spacing between two grounding points remains at $200 \mathrm{~m}$. In these cases, the relationship between installing spacing and LWL can be drawn out for lightning striking to ground wire, as shown in Fig. 6.

Fig. 6 illustrates that the lowest LWL declines following

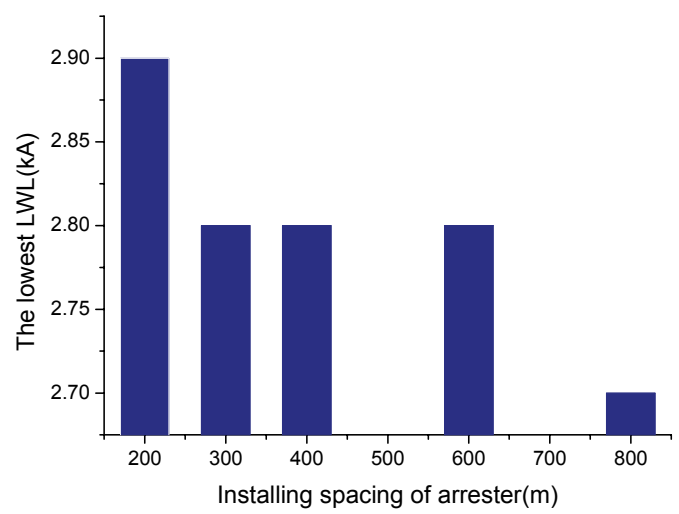

Fig. 6 Relationship between installing spacing of arrester and the lowest LWL for lightning striking to ground wire

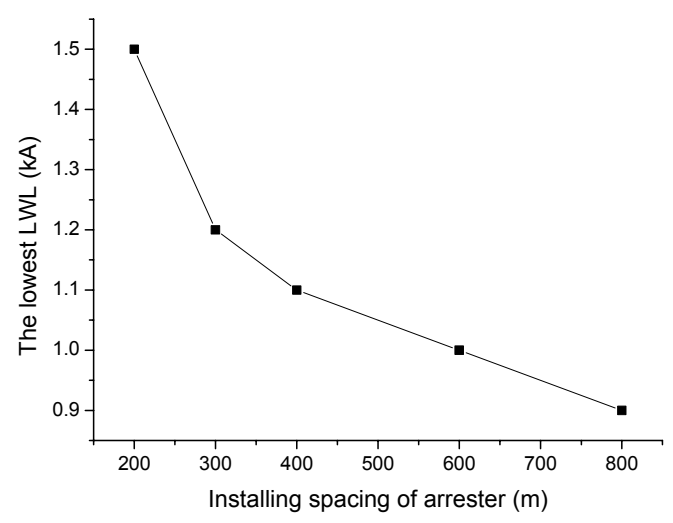

Fig. 7 Relationship between installing spacing of arrester and the lowest LWL for lightning striking to catenary installing spacing increases for lightning striking to ground wire. The lowest LWL declines a bit fast as the installing spacing increases from $200 \mathrm{~m}$ to $300 \mathrm{~m}$. As the installing spacing increases from $300 \mathrm{~m}$ to $600 \mathrm{~m}$, the lowest LWL nearly has no change. As a whole, the lowest LWL declines not much with increasing installing spacing. So it can be concluded in these cases that installing spacing of arrester has weak effect on LWL for lightning striking to ground wire.

The relationship curve between installing spacing of arrester and LWL can be drawn out for lightning striking to catenary, as shown in Fig. 7.

Fig. 7 illustrates that the lowest LWL declines obviously following installing spacing increases for lightning striking to catenary. The lowest LWL declines about $20 \%$ as the installing spacing increases from $200 \mathrm{~m}$ to $300 \mathrm{~m}$. As the installing spacing increases from $200 \mathrm{~m}$ to $800 \mathrm{~m}$, the lowest LWL declines about $40 \%$. It is mainly due to the limited protecting scope of arrester that the lowest LWL declines following installing spacing increases. Then, it can be concluded that installing spacing of arrester obviously affects LWL and decrease installing spacing of arrester can make a contribution to improve the lowest LWL for lightning striking to catenary.

\section{LWL with Different Erecting Spacing Between Two Grounding Points}

\subsection{LWL with $300 \mathrm{~m}$ erecting spacing}

Here keep the $200 \mathrm{~m}$ installing spacing between two arresters recommended by standard and other conditions, except for the erecting spacing between two grounding points. It means arrester is still set at NO.3 and NO.7 pillars. LWL can be evaluated after lightning striking to ground wire or catenary at each pillar based on established MLSC. It adopts $300 \mathrm{~m}$ spacing to erect grounding points, namely grounding point is set at NO.3 and NO.9 pillars.

Lightning strike points are located on the top of NO.3 to NO.9 pillars when lightning stroke occurs on ground wire. LWL and breakdown situations of insulators can be evaluated, as shown in Table 5.

Table 5 illustrates that the lowest LWL (2.9kA) occurs

Table 5. LWL with $300 \mathrm{~m}$ erecting spacing of grounding point for lightning striking to ground wire at each pillar

\begin{tabular}{c|c|c}
\hline Striking point & Breakdown insulator & LWL \\
\hline NO.3 pillar & NO.6 insulator & $7.2 \mathrm{kA}$ \\
\hline NO.4 pillar & NO.5 insulator & $3.5 \mathrm{kA}$ \\
\hline NO.5 pillar & NO.5 insulator & $2.9 \mathrm{kA}$ \\
\hline NO.6 pillar & NO.5 insulator & $3.4 \mathrm{kA}$ \\
\hline NO.7 pillar & NO.5 insulator & $3.5 \mathrm{kA}$ \\
\hline NO.8 pillar & NO.8 insulator & $4.1 \mathrm{kA}$ \\
\hline NO.9 pillar & NO.5 insulator & $7.1 \mathrm{kA}$ \\
\hline
\end{tabular}


Table 6. LWL with $300 \mathrm{~m}$ installing spacing OF grounding point for lightning striking to catenary AT EACH PILLAR

\begin{tabular}{c|c|c}
\hline Striking point & Breakdown insulator & LWL \\
\hline NO.3 pillar & NO.6 insulator & $6.9 \mathrm{kA}$ \\
\hline NO.4 pillar & NO.4 insulator & $2.6 \mathrm{kA}$ \\
\hline NO.5 pillar & NO.5 insulator & $1.4 \mathrm{kA}$ \\
\hline NO.6 pillar & NO.6 insulator & $2.6 \mathrm{kA}$ \\
\hline NO.7 pillar & NO.8 insulator & $5.3 \mathrm{kA}$ \\
\hline NO.8 pillar & NO.7 insulator & $2.6 \mathrm{kA}$ \\
\hline NO.9 pillar & NO.9 insulator & $1.4 \mathrm{kA}$ \\
\hline
\end{tabular}

for lightning striking to NO.5 pillar with $300 \mathrm{~m}$ erecting spacing between two grounding points. The highest LWL (7.2kA and 7.1kA) occurs for lightning striking to NO.3 or NO.9 pillar due to grounding point on the both, which obviously improves LWL for lightning striking to ground wire. As can be noticed, LWL improves a bit for lightning striking to NO.7 pillar because of installing arrester on it.

Lightning strike points are located on catenary beside insulators of NO.3 to NO.9 pillars for lightning shielding failure. The LWL and breakdown situations of insulators can be evaluated, as shown in Table 6 .

Table 6 illustrates that the lowest LWL (1.4kA) occurs for lightning shielding failure of catenary beside NO.5 pillar, it is most likely to flashover on the insulator of NO.5 pillar. The highest LWL (6.9kA) occurs for lightning shielding failure of catenary beside NO.3 pillar because of grounding point and arrester on this pillar. Beside NO.7 pillar, LWL (5.3kA) obviously improves due to arrester on NO.7 pillar. However, beside NO.9 pillar, grounding point of NO.9 pillar have nearly no effects on LWL. It can be concluded in these cases that grounding point has nearly no effects on LWL for lightning shielding failure of catenary.

\subsection{LWL with various erecting spacing}

For studying how the erecting spacing between two grounding points dose affect LWL, this part comparatively analyzes the lowest LWL with various erecting spacing, including $200 \mathrm{~m}, 300 \mathrm{~m}, 400 \mathrm{~m}, 600 \mathrm{~m}, 800 \mathrm{~m}$ erecting spacing. The installing spacing between two arresters remains at $200 \mathrm{~m}$. In these cases, the relationship between erecting spacing and LWL can be drawn out for lightning striking to ground wire, as shown in Fig. 8.

Fig. 8 illustrates that the lowest LWL declines a bit following erecting spacing increases for lightning striking to ground wire. The lowest LWL declines about $0.1 \mathrm{kA}$ as the spacing increases from $200 \mathrm{~m}$ to $800 \mathrm{~m}$. The main cause leading to this phenomenon is that the pillar struck by lightning is far from grounding pillar, large spacing make a construction to scatter lightning surge difficultly.

The relationship between erecting spacing of grounding points and LWL can be drawn out for lightning striking to catenary, as shown in Fig. 9.

Fig. 9 illustrates that the lowest LWL has no changes

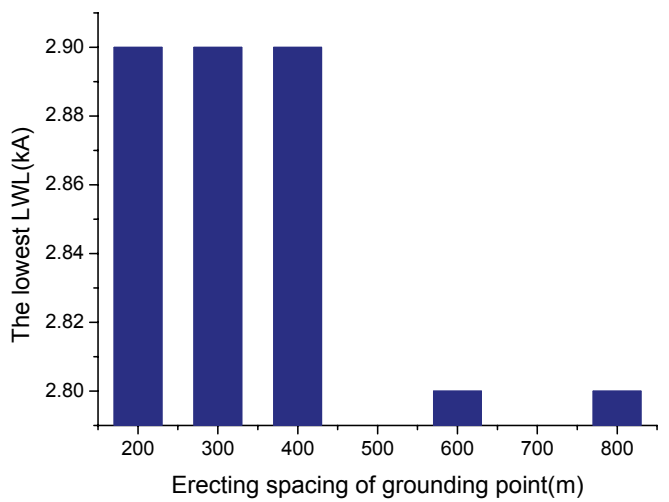

Fig. 8 Relationship between erecting spacing of grounding point and lowest LWL for lightning striking to ground wire

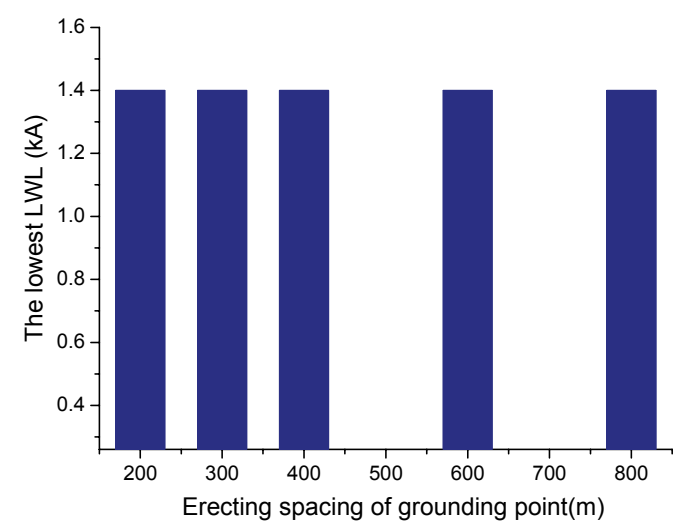

Fig. 9 Relationship between erecting spacing of grounding points and lowest LWL for lightning striking to catenary

following erecting spacing increases between two grounding points for lightning striking to catenary. The lowest LWL is not affect by erecting spacing as the spacing changes from $200 \mathrm{mto} 800 \mathrm{~m}$. The main cause leading to this phenomenon is that the arrester installed across every $200 \mathrm{~m}$ can effectively protect near insulators against breakdown. It can be concluded that erecting spacing between grounding points has weak effect on the lowest LWL for lightning striking to catenary.

\section{Comprehensive LPS using Both Arrester and Grounding Points}

Combined with the previous study we found that grounding point can obviously improves LWL for lightning striking to ground wire. Therefore, this part analyzes the situation in depth that smaller erecting spacing of grounding point, including three cases, $50 \mathrm{~m}$ (each pillar is set grounding points), $100 \mathrm{~m}, 200 \mathrm{~m}$. Taking into account more dense arresters will result in increasing cost of subway construction and workload of operation maintenance, 


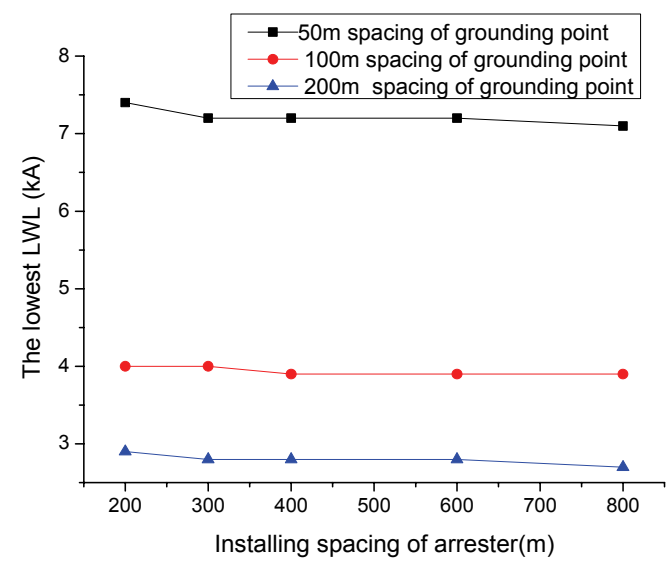

Fig. 10 Relationship between the lowest LWL and protection measures for lightning striking to ground wire

arrester is installed with $200 \mathrm{~m}, 300 \mathrm{~m}, 400 \mathrm{~m}, 600 \mathrm{~m}$ and $800 \mathrm{~m}$ spacing. Through a variety of programs where grounding points and arresters are comprehensively used, comprehensive assessment of lightning protecting effect of catenary can be achieved. For lightning striking to ground wire, lightning strike points are located at the middle of spacing between two grounding points, the lowest LWL of catenary can be analyzed, the results are as shown in Fig. 10.

Fig. 10 illustrates that the LWL of catenary is principally affected by erecting spacing of grounding point rather than the installing spacing of arrester for lightning striking to ground wire. The lowest LWL is $7.2 \mathrm{kA}$ for $50 \mathrm{~m}$ erecting spacing of grounding point. For $100 \mathrm{~m}$ erecting spacing of grounding point, the lowest LWL is about $4 \mathrm{kA}$. For $200 \mathrm{~m}$ erecting spacing of grounding point, the lowest LWL is about $2.9 \mathrm{kA}$. For each grounding pillar, the lowest LWL is 2.5 times than that of $200 \mathrm{~m}$ existing grounding scheme. For erecting spacing of grounding point is lower than $200 \mathrm{~m}$, the effects of scattering lightning surge through pillars is better and the lowest LWL of lines can improves more. Considering the viaduct piers of subway are reserved ground terminal, the lowest LWL of lines can improves by grounding pillars through piers. The cost of grounding each pillar is not high, whereas grounding each pillar can remarkably improves the lowest LWL of catenary.

For lightning striking to catenary, the lightning strike points are located at the middle of spacing between two arresters, the lowest LWL of catenary can be analyzed, the results are as shown in Fig. 11.

Fig. 11 illustrates that the lowest LWL of catenary is principally affected by installing spacing of arrester rather than erecting spacing of grounding point. The lowest LWL declines following the installing spacing of arrester increases. There are differences in LWL between two conditions that are $50 \mathrm{~m}$ erecting spacing and $100 \mathrm{~m}$ or $200 \mathrm{~m}$ erecting spacing of grounding point, mainly because intensive grounding points could more effectively eliminate

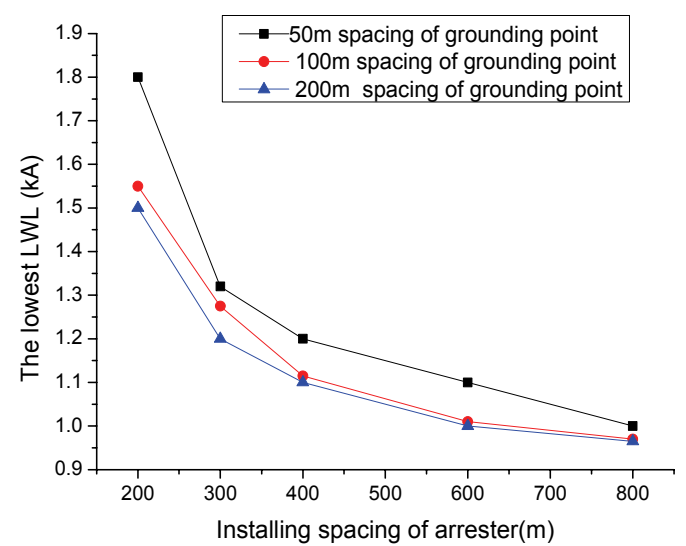

Fig. 11 Relationship between the lowest LWL and protection measures for lightning striking to catenary

the inductor voltage. For the $200 \mathrm{~m}$ to $400 \mathrm{~m}$ installing spacing of arrester, the lowest LWL improves obviously following the installing spacing declines. Installing spacing of arrester has weak effect on LWL of catenary under a condition that the spacing is greater than $600 \mathrm{~m}$. Installing spacing of arrester can be chosen properly according to lightning damage degree and reliability requirements in construction site.

\section{Conclusions}

According to established MLSC, this paper evaluates LWL of catenary with viaduct of subway in Guangzhou with existing LPS and analyzes the effect on the LWL with various setting manners of arrester and grounding point. Four conclusions can be achieved as follows:

The highest LWL emerges at the pillars of catenary's both ends with existing LPS in Guangzhou, mainly due to erection of both grounding point and arrester. Comparatively, the lowest LWL emerges at the pillars of catenary's middle.

Grounding point improves obviously LWL of catenary for lightning striking to ground wire and arrester improves obviously the LWL for lightning striking to catenary.

Using more arresters is less effective than grounding each pillars. Grounding each pillar could make the lowest LWL increase to 2.5 times than that of $200 \mathrm{~m}$ existing grounding scheme for lightning striking to ground wire. However, installing arrester across every $200 \mathrm{~m}$ could only improve the lowest LWL to 1.5 times than that of installing arrester across every $800 \mathrm{~m}$. In addition, the reserved grounding terminals could change grounding mode easily even almost no cost while increasingly installing every arrester would cost 2000 to 3000 RMB. As known to all, a recommended method in engineering should be effective, easy to practice and less drawback. But using more arresters also means higher fault rate of system. All the reasons 
could greatly support the proposing recommendation that each pillar could be grounded for subway catenary system with viaduct.

\section{Acknowledgment}

This work was supported by the National Natural Science Funds for Distinguished Young Scholar of China (No.51507145) and Fundamental Research Funds for the Central Universities of China(No.2682014CX022). The authors would like to thanks the reviewers for their valuable comments that helped us to improve the quality of the paper.

\section{References}

[1] Le. Zhao, Li. Keping, Ye. Jingjing and Xu. Xiaoming, "Optimizing the train timetable for a subway system," Proceedings of the Institution of Mechanical Engineers, Part F: Journal of Rail and Rapid Transit, vol. 229, no. 8, pp. 852-862, Nov. 2015.

[2] Xu. Xiaoming, Li. Keping and Li. Xiang, "Research on passenger flow and energy consumption in a subway system with fuzzy passenger arrival rates," Proceedings of the Institution of Mechanical Engineers, Part F: Journal of Rail and Rapid Transit, vol. 229, no. 8, pp. 863-874, Nov. 2015.

[3] Abdi A and Ghanbarpour A, "Is there an optimum internal diameter for subway tunnels in terms of economic and technical viewpoints," Proceedings of the Institution of Mechanical Engineers, Part F, vol. 230, no. 1, pp. 56-63, Jan. 2016.

[4] GB $50490-2009$, Technical code of urban rail transit.

[5] Yi. Dongbing, "Urban Rail Transit Catenary Lightning Protection System Analysis," Electrified Railway, vol. 1, no. 2, pp. 40-43, Apr. 2013.

[6] Tian.Yu, "Research on the Lightning Protection of OCS in Tianjin-Binhai Light rail," Railway Engineering Society, vol. 31, no. 5, pp. 90-94, May. 2014.

[7] Yang. Shiwu, Chen. Lei, Roberts. Clive and Wang. Xinghui, "Case study: Feature-based analysis of electric arc damage to railway signal cables," Proceedings of the Institution of Mechanical Engineers, Part F: Journal of Rail and Rapid Transit, vol. 229, no. 1, pp. 3-11, Jan. 2015.

[8] Jiang. Liu, Bai-gen. Cai and Jian Wang, "Early warning system for potential train collisions: enhancing safety levels of high-speed trains," Proceedings of the Institution of Mechanical Engineers, Part F: Journal of Rail and Rapid Transit, vol. 230, no. 1, pp. 295-312, Jan. 2016.

[9] Fröhling. R, De. Koker J and Amade. M, "Rail lubrication and its impact on the wheel/rail system,"
Proceedings of the Institution of Mechanical Engineers, Part F: Journal of Rail and Rapid Transit, vol. 223, no. 2, pp. 173-183, Mar. 2009.

[10] Bian. Kai, Chen. Weijiang, Wang. Litian, Shen. Haibin, Li. Chengrong, Wang. Yanli and Zhao. Haijun, "Lightning protection of traction power supply catenary of high-speed railway", Proceedings of the CSEE, vol. 33, no. 10, pp. 191-199, Apr. 2013.

[11] Cao. Xiaobin, Xiong. Wanliang, Wu. Guangning, Li. Ruifang and Zhou. Lijun, "Lightning Scope Division and Lightning Trip-out Rate Calculation Method for Overhead Catenary System," High Voltage Engineering, vol. 39, no. 6, pp. 1515-1521, June.2013.

[12] Cheng. Hongbo, He. Zhengyou, Hu. Haitao, Mu. Xiuqing and Wang. Bin, "Risk assessment and early warning of lightning disaster for traction power supply system of high-speed railway," Journal of the China Railway Society, vol. 35, no. 5, pp. 21-26, May.2013.

[13] Bian. Kai, Chen. Weijiang, Shen. Haibin, Li. Chengrong, Wang. Litian, Zhao. Haijun, Wang. Yanli, Yin. Bin and Li. Qingyu, "Development of metal oxide surge arrester with series gap for traction power supply system catenary of high-speed electrified railway," Proceedings of the CSEE, vol. 33, no. 10, pp. 200-209, Apr.2013.

[14] Shen. Haibin, Chen. Weijiang, Bian. Kai and Chen. Kang, "Experimental Studies on Application Characteristics of Lightning Protection for Long Rod Suspension Composite Insulators for High-speed Railway Catenary," High Voltage Engineering, vol. 41, no. 5, pp. 1574-1581, May.2015.

[15] Wang. Shunchao, He. Jinliang and Chen. Weijiang, "Simulation and analysis of lightning overvoltage of $10 \mathrm{kV}$ cable on the bridge of high-speed railroad," High Voltage Engineering, vol. 37, no. 3, pp. 613621, Mar.2011.

[16] Wu. Guangning, Huang. Bo, Cao Xiaobin, Cui.. Yunguang and Gao. Feng, "Lightning Impulse Characteristic of Integrated Grounding System of High-speed Railway Roadbed Section," Power System Technology, vol. 40, no. 3, pp. 669-675, Mar.2014.

[17] Ma. Jiuyang, "The characteristic analysis of the highspeed railway roadbed sections integrated grounding system,' China Academy of Railway Science, Beijing, China, May 2011.

[18] GB 50157-2013, Code for design of metro.

[19] Zhao. Haijun, Chen. Wei jiang, Shen Haibin and Bian. Kai, "Research on the Lightning Protection Effect of Metro Overhead Ground Wire," Journal of Railway Engineering Society, vol. 32, no. 1, pp. 122128, Jan. 2015.

[20] Cao. Jianshe, "The Evaluation of the Lightning Protection of the Protection Lline Served as the Lightning Line on the Passenger Dedicated Line," 
China Railway Science, vol. 34, no. 6, pp. 79-83, Nov.2013.

[21] He. JinLiang and Wu. Weihan, "Adopting line surge arresters to increase lightning-withstand levels of transmission-lines," in Proceedings of IEEE Computer, Communication, Control and Power Engineering 1993 Conference, Beijing, China, October 1993.

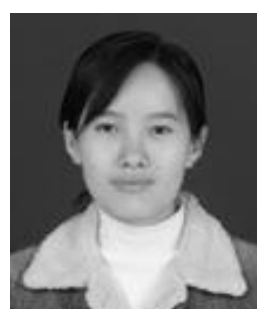

Ruifang Li She received the B.Sc., M.Sc. and Ph.D. degrees in electrical engineering from Southwest Jiaotong University, Chengdu, China, respecttively in 2002, 2005, and 2012. She has tutored master candidates devoting to researches about lightning protection and grounding technology last for

several years.

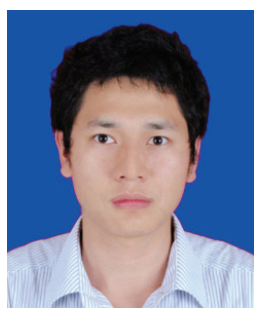

Kui Chen $\mathrm{He}$ received the B.Sc. degree in electrical engineering from Hainan University, China, in 2012, and the M.E. degree in electrical engineering from Southwest Jiaotong University, China, in 2016. He is now a Ph.D. candidate in the Laboratory OPERA and Research Federation FCLAB, University of Technology Belfort-Montbeliard. His major research interest is overvoltage and sliding mode control.

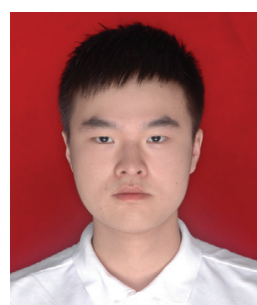

Lisheng Chen He received the B.Sc degree from South West University of Science and Technology, Mianyang, Sichuan, China, in 2015, with major of electrical engineering and now he is a M.Sc. degree candidate in High Voltage Lab of Southwest Jiaotong University, Chengdu, Sichuan, China, with research major of overvoltage and lightning protection of railway.

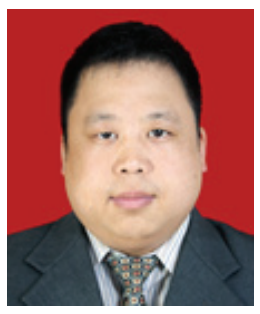

Xiaobin Cao He received the B.Sc. and Ph.D. degrees in electrical engineering from Southwest Jiaotong University, Chengdu, China, respectively in 1996 and 2011. Currently, he is an Associate Professor in the School of Electrical Engineering, Southwest Jiaotong University and his research interests are grounding technology and overvoltage protection.

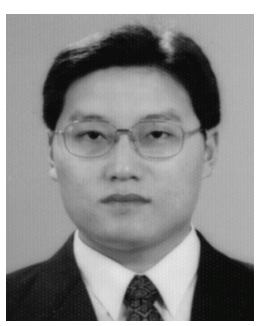

Guangning Wu He received the B.Sc., M.Sc. and Ph.D. degrees in electrical engineering from Xi'an Jiaotong University, respectively in 1991, 1994and 1997. Currently, he is a Professor in the School of Electrical Engineering, Southwest Jiaotong University. His research interests include condition monitoring, fault diagnosis and insulation life-span evaluation for electric power equipment.

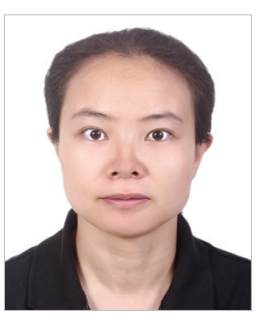

Xueqin Zhang She received the B.Sc. and $\mathrm{Ph} . \mathrm{D}$. degrees in electrical engineering from Southwest Jiaotong University, Chengdu, China, respectively in 2002 and 2007. Currently, she is an Associate Professor in the School of Electrical Engineering, Southwest Jiaotong University and her research interests are high voltage outdoor insulation and overvoltage protection. 